\title{
Frailty and Acute Kidney Injury: a 1-Year Follow-up of a Prospective Cohort
}

\author{
Sarah Morton, MBBS MRCP MRCEM ${ }^{7}$, Alexander Isted, MBBS ${ }^{7}$, \\ Pascale Avery, MBBS MRCEM ${ }^{7}$, and Joe Wang, MBBS MRCP PhD ${ }^{1,2}$

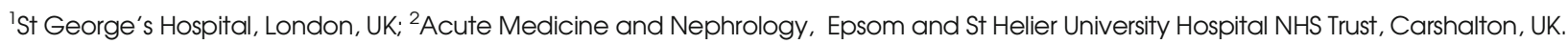

J Gen Intern Med 34(8):1390-1

DOI: $10.1007 / \mathrm{s} 11606-019-04986-9$

(c) Society of General Internal Medicine 2019

\section{INTRODUCTION}

The demand that acute kidney injury (AKI) places on the healthcare system is well documented, with both increased morbidity and mortality. ${ }^{1}$ The Clinical Frailty Score (CFS) is a tool developed to assess an individual's level of frailty and we have previously demonstrated an association between CFS and $\mathrm{AKI} .{ }^{2}$ At 2 weeks following an acute medical admission, there is a higher mortality in those who are both "severely frail" (a frailty score of 7 to 9) and have an AKI on presentation than those who are frail or have AKI in isolation. ${ }^{3}$ However, there is currently no information regarding longer term outcomes in this group. We present 1-year follow-up data for our prospective cohort. ${ }^{3}$

\section{METHODS}

This was a single-centre prospective cohort study. The 2-week data has been previously published. ${ }^{3}$ Data were collected on unselected acute medical admission and takes over 12 nonconsecutive days in June-July 2017. All patients aged $\geq 65$ were included and given a CFS based on preadmission status. ${ }^{2} \mathrm{~Pa}-$ tients with a CFS of 1-4 were deemed "no significant frailty", 56 "mild to moderately frail" and 7-9 "severely frail". Baseline creatine was determined by results over the previous year; patients were excluded if no baseline creatinine was available or if they were currently receiving renal replacement therapy. AKI was staged as per the Kidney Disease: Improving Global Outcomes parameters. ${ }^{4}$ Outcome measures of mortality and emergency re-attendance to hospital were assessed at 1 year following admission alongside the data previously analysed. Data were analysed using SPSS statistics. A $p$ value $<0.05$ was considered statistically significant. No ethical approval was required, and a STROBE checklist was followed.

\section{RESULTS}

All 164 patients ( 77 male) were reviewed at 1 year. Thirty-one patients (19\%) had an AKI on admission (28 patients, stage 1;

Published online April 3, 2019
3 patients, stage 2). A total of 50 out of 164 had died at 1 year $(30.5 \%)$.

AKI at presentation remained significantly associated with death at 1 year (55.6\% AKI group vs $29.7 \%$ no AKI group; $p=$ $0.02)$ resulting in a relative risk (RR) of 1.84 (95\% CI 1.162.92). There was no difference in re-attendances between the groups. Aside from AKI, only ischaemic heart disease (RR 0.51; 95\% CI 0.27-0.98, $p=0.03$ ) and active malignancy (RR 2.27; 95\% CI $1.45-3.57, p<0.01)$ were found to be significantly associated with mortality at follow-up (Table 1).

There remained a significantly increased rate of death at 1 year in those who were severely frail ( $47.2 \%$ of group) versus no frailty $(22.2 \%)$ or mild-moderate frailty $(27.75 \%)$ respectively $(p=0.02$ and $p=0.04)$. There was no significant difference in re-attendances between the frailty groups. Having both AKI and severe frailty resulted in a statistically significant relative risk of death at 1 year of $2.79(95 \%$ CI $1.66-4.71, p<0.01)$ compared to these risk factors alone (Table 2).

\section{DISCUSSION}

Patients who were both severely frail and had an AKI were found most likely to die at 1 year (relative risk of $2.79(95 \% \mathrm{CI}$ 1.66-4.71)). At 2 -week follow-up, $36.3 \%$ of patients who were severely frail and had an AKI died ${ }^{3}$; a further $30.4 \%$ of

Table 1 One-Year Mortality Risk Factors

\begin{tabular}{|c|c|c|c|c|c|}
\hline \multirow[t]{2}{*}{ Variable } & \multicolumn{2}{|c|}{$\begin{array}{l}\text { Died at } \\
1 \text { year } \\
(n=50)\end{array}$} & \multicolumn{2}{|c|}{$\begin{array}{l}\text { Alive at } \\
1 \text { year }\end{array}$} & \multirow[t]{2}{*}{$p$} \\
\hline & $n$ & $\%$ & $n$ & $\%$ & \\
\hline AKI & 15 & 30.0 & 16 & 14.0 & $0.02 *$ \\
\hline Ischemic heart disease & 9 & 18.0 & 40 & 35.1 & $0.03 *$ \\
\hline Chronic kidney disease & 7 & 14.0 & 14 & 12.3 & 0.76 \\
\hline Hypertension & 25 & 50.0 & 61 & 53.5 & 0.68 \\
\hline $\begin{array}{l}\text { Cerebrovascular accident/ } \\
\text { transient ischemic attack }\end{array}$ & 8 & 16.0 & 16 & 14.0 & 0.74 \\
\hline Heart failure & 7 & 14.0 & 12 & 10.5 & 0.52 \\
\hline Dementia & 14 & 28.0 & 21 & 18.4 & 0.17 \\
\hline Diabetes & 14 & 28.0 & 32 & 28.1 & 0.99 \\
\hline Parkinson's disease & 3 & 6.0 & 5 & 4.4 & 0.66 \\
\hline $\begin{array}{l}\text { Chronic obstructive pulmonary } \\
\text { disease }\end{array}$ & 13 & 26.0 & 20 & 17.5 & 0.21 \\
\hline Active malignancy & 12 & 24.0 & 8 & 7.0 & $<0.01 *$ \\
\hline Previous malignancy & 6 & 12.0 & 8 & 7.0 & 0.29 \\
\hline
\end{tabular}

$*_{p}<0.05$ statistically significant 
Table 2 Comparison Between Combination of Groups with Mortality at 1 Year

\begin{tabular}{|c|c|c|c|}
\hline & $\begin{array}{l}\text { Died at } \\
1 \text { year }(\%)\end{array}$ & $\begin{array}{l}\text { RR of death at } \\
1 \text { year* }\end{array}$ & $p$ \\
\hline $\begin{array}{l}\text { AKI and severely frail } \\
(n=12)\end{array}$ & $8(66.7)$ & $\begin{array}{l}2.79(95 \% \mathrm{CI} \\
1.66-4.71)\end{array}$ & $<0.01^{\dagger}$ \\
\hline $\begin{array}{l}\text { AKI and not severely } \\
\text { frail }(n=19)\end{array}$ & 7 (36.8) & $\begin{array}{l}1.54(95 \% \mathrm{CI} \\
0.78-3.04)\end{array}$ & 0.21 \\
\hline $\begin{array}{l}\text { Not AKI and severely } \\
\text { frail }(n=24)\end{array}$ & $9(37.5)$ & $\begin{array}{l}1.57(95 \% \mathrm{CI} \\
0.85-2.91)\end{array}$ & 0.15 \\
\hline $\begin{array}{l}\text { Not AKI and not } \\
\text { severely frail }(n=109)\end{array}$ & $26(23.9)$ & & \\
\hline
\end{tabular}

*Control group those without AKI and not severely frail $(C F S<7)$ $t p<0.05$ statistically significant

these patients had died by 1 year resulting in a mortality of $66.7 \%$ in this group. This is a higher relative risk of mortality at 1 year than those who had an active malignancy or ischaemic heart disease, which were the only other risk factors found to be significantly associated with 1-year mortality. Whilst it might be expected that increased frailty would be associated with more hospital re-attendances, this was not shown to be the case.

Whilst it remains unclear about the exact underlying physiological changes that occur, this evidence continues to suggest that the CFS could be used as a surrogate marker of these changes. We again support the use of CFS as a bedside test for predicting not only the development of AKI in acute illness, but the combination being a predictor of mortality at 1 year. ${ }^{3}$ It may be that this could be used in particular when discussing with patients and families about end-of-life planning.

Corresponding Author: Joe Wang, MBBS MRCP PhD; Acute Medicine and Nephrology Epsom and St Helier University Hospital NHS Trust, Carshalton, UK (e-mail: joe.wang@nhs.net).

\section{Compliance with Ethical Standards:}

Conflict of Interest: The authors declare that they do not have a conflict of interest.

Publisher's Note: Springer Nature remains neutral with regard to jurisdictional claims in published maps and institutional affiliations.

\section{REFERENCES}

1. Waikar SS, Liu KD, Chertow GM. Diagnosis, epidemiology and outcomes of acute kidney injury. Clin J Am Soc Nephrol 2008;3:844-61.

2. Rockwood K, Song XW, Macknight C, et al. A global clinical measure of fitness and frailty in elderly people. CMAJ. 2005; 173:489-95.

3. Morton S, Isted A, Avery $\mathbf{P}$, Wang $\mathbf{J}$. Is frailty a predictor of outcomes in elderly inpatients with acute kidney injury? A prospective cohort study. Am J Med 2018;131:1231-56.

4. Khwaja A. KDIGO Clinical Practice Guidelines for Acute Kidney Injury. Nephron Clin Pract 2012;120:C179-C84.

Publisher's Note Springer Nature remains neutral with regard to jurisdictional claims in published maps and institutional affiliations. 